\title{
Synthesis of New Arylsulfonylhydrazide-1,2,3-Triazole Derivatives from Diazocarbonyl Compound
}

\section{Vinícius Rangel Campos ${ }^{\mathrm{a}}$, Flaviana Rodrigues Filteman Dias ${ }^{\mathrm{a}}$, Vitor Francisco Ferreira $^{\mathrm{a}}$, Maria Cecília Bastos Vieira de Souza ${ }^{\mathrm{a}}$ and Anna Claudia Cunha ${ }^{\mathrm{a} *}$}

${ }^{a}$ Universidade Federal Fluminense, Departamento de Química Orgânica, Outeiro de São João Batista, s/nº, Niterói, 24120-050, Rio de Janeiro, Brazil.

*corresponding author. Tel.: +55 21 26292364; Fax: +55 21 26292135; e-mail: annac@vm.uff.br Keywords: 1,2,3-triazoles, antiviral and arylsulfonylhydrazide

\section{INTRODUCTION}

Recently, we described the synthesis and pharmacological evaluation of 1,2,3-triazole derivatives. ${ }^{1}$ In this study, it was found that the compounds 1-[(5"'-methyl-1"'-(4"'" fluorophenylamino)-1H-1,2,3-triazol-4"'-yl)carbonyl]2-(4'methylphenylsulfonyl)hydrazine and 1-[(5'methyl-1'-(2",5"-dichlorophenylamino)-1H-1,2,3triazol-4'-yl)carbonyl]-2-(phenylsulfonyl)hydrazine exhibited a significant effect against HSV-1 replication in cell culture. In an effort to optimize the antiviral activity of these structurally triazole compounds, we now described the synthesis of a new family of triazol derivates 1a-f.

\section{RESULTS AND DISCUSSION}

The synthesis of these new derivatives 1a-f is shown in Scheme 1. The 1,2,3-triazoles $\mathbf{2 a - b}$ were prepared in moderated yields by the condensation of ethyl 2-diazoacetoacetate with corresponding arylsulfonylhydrazides according to the method described in our previous report. ${ }^{2}$ These compounds were converted into their corresponding carbohydrazides $3 \mathbf{a}-\mathbf{b}$ by treatment with hydrazine hydrate in refluxing ethanol. ${ }^{3}$ Finally, the new class of triazole derivatives 1a-f was prepared in moderated yields by the reaction of compounds $\mathbf{3} \mathbf{a}-\mathbf{b}$ with suitable arylsulfonyl chlorides $\mathbf{4 a - c}$ in pyridine. The structures of these new compounds were fully characterized by IR and ${ }^{1} \mathrm{H}$ NMR spectroscopies.
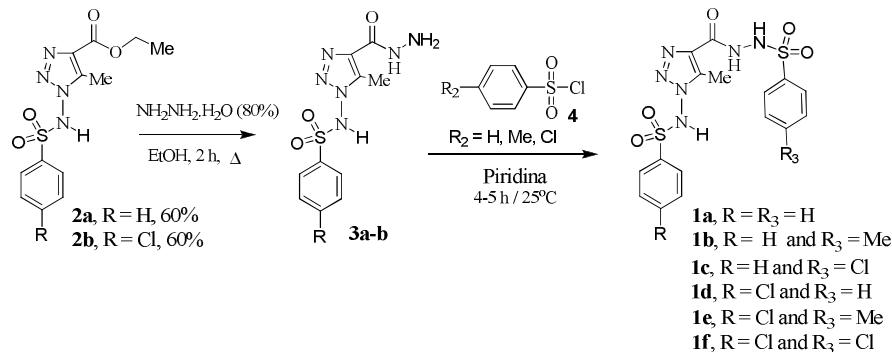

Scheme 1. Synthesis of the new arylsulfonylhydrazide-1,2,3-triazole derivatives 1a-f.

\section{CONCLUSION}

In conclusion, we have developed the synthesis of a new series of arylsulfonylhydrazide-1,2,3triazole derivatives 1a-f by the reaction of carbohydrazide compounds $\mathbf{3 a - b}$ with suitable arylsulfonyl chlorides $4 a-c$ in pyridine. Our further efforts will be dedicated towards evaluating the biological profiles of these compounds.

\section{ACKNOWLEDGEMENTS}

This work was supported by the Brazilian agency FAPERJ-Pronex. Fellowship granted to UFF, by FAPERJ, CAPES, CNPq-PIBIC is gratefully acknowledged.

\section{REFERENCES}

${ }^{1}$ Jordão, A. K.; Ferreira, V. F.; Souza, T. M. L.; Faria, G. G. S.; Machado, V.; Abrantes, J. L.; Souza, M. C. B. V.; Cunha, A. C. Bioorg. Med. Chem. 2011, 19, 1860.

2 Campos, V. R.; Abreu, P. A.; Castro, H. C.; Rodrigues, C. R.; Jordão, A. K.; Ferreira, V. F.; Souza, M. C. B. V.; Santos, F. C.; Moura, L. A.; Domingos, T. S.; Sanchez, E. F. Fuly, A. L.; Cunha, A. C. Bioorg. Med. Chem. 2009, 17, 7429.

3 Jordão, A. K.; Afonso, P. P.; Ferreira, V. F.; De Souza, M. C. B. V. Almeida, M. C. B.; Beltrame, C. O.; Paiva, D. P.; Wardell, S. M. S. V.; Wardell, J. L.; Tiekink, E. R. T.; Damaso, C. R.; Cunha, A. C. Eur. J. Med. Chem. 2009, 44, 3777. 